\title{
Tourism strategy at Swedish Transport Administration
}

\author{
C. Ahnlund \\ Swedish Transport Administration, Sweden
}

\begin{abstract}
The Swedish Transport Administration's (STA) vision is to make the good journey possible by providing individuals and the business community with the best options for transport and travel. The STA has divided their clients into various customer groups depending on their needs and demands for the good journey. The tourism industry is one of the major strategic customer groups identified by the STA.

The demands and needs from the tourism industry have been described in a customer group document. The tourism industry is dependent on good road services and sign-posting. It must be made easy for the tourist to find their way to their destination and also made possible to find and use environmentally friendly options for their travel needs.

STA can in the best way possible meet the demands and needs from the tourist industry by enhancing the tourist signs and information along the roads, by developing dialogue between the tourist industry and STA and by supporting mobility management.

The STA has worked together with the tourism industry on a national and regional level in order to enhance the possibility for regional development of the tourism industry. We have found that a lot more can be done if we increase the knowledge and coordination of issues important for tourism development.

In this paper we will describe the tools and methods used to create a strategy for the tourism industry. The survey has been divided into three different steps, which are: state of the art, co-operation with the tourism industry and economic analysis and effects describing the tourism industry. The tourism strategy will help the SRA to clarify the goal for our services and co-operation with the tourism industry and to identify key areas for achieving our goal.
\end{abstract}

Keywords: tourism strategy, Swedish Transport Administration. 


\section{Background and objectives}

The Swedish Transport Administration (STA) is responsible for building, operating and maintaining the national roads and railways. The operations of the STA began on 1 April 2010 and, in conjunction with its start, the STA took over the operations of the then Swedish Road Administration, Swedish Rail Administration and also minor parts of other transport authorities. The STA pursues national activities, with six regional offices that are responsible for customer contacts in their particular regions.

The STA has classified its customers into different strategic groups, based on their needs and demands on the transport system. The needs of each customer group are described in a customer group document [2] on the basis of the needs that the customer group itself has expressed for being able to complete a good journey. The tourist industry is one of the STA strategic customer groups.

The tourist industry in Sweden consists of companies and organizations that offer services and experiences to its customers, who are tourists. The Swedish concept of tourist includes both leisure travellers and those who make longer journeys on business. The customer group embraces many different types of activities, ranging from a small roadside café to leisure centres such as Astrid Lindgren's World or the Kolmården Adventure Park.

The tourist industry operates both in rural and in urban areas, and it may be scattered and operate in large areas or it may be highly concentrated to one place. Transport consists mainly of the journeys of visitors to and within the area or place. Around two million tourists arrive in Sweden by ferry and about 5.5 million arrive by air. The car is the most common means of transport within Sweden for both leisure and business travellers, except for journeys in excess of 600 kilometres. The pattern of transport varies very widely and may impose heavy strains on the transport system at certain times of the year, such as during the winter tourist period in the highlands or during the summer in the south of the country.

The entire industry is growing rapidly and is becoming increasingly important as a motor for growth and development, both in big cities and in sparsely populated rural areas. The tourist industry is engaged on reviewing the targets and strategies for continued rapid development, and sees opportunities for extensive increases, given the right input. This will make heavy demands on adaptation and development of the transport system. In order to meet future demands that the tourist industry will be making on the transport system, the STA will need to review its targets and the forms of cooperation with the tourist industry.

The continued work is described as developing a strategy for the tourist industry, with concrete targets for the support provided by the STA to the industry. 


\section{Needs of the tourist industry}

The journey destinations shall be accessible to visitors. Important factors in meeting this requirement are the availability of good communications in the form of roads, railways, parking facilities and information before and during the journey. The journey to and from the destination is of great importance in enabling the tourist industry to offer a positive overall experience. Good accessibility, good maintenance and reliable connections are therefore needed. It is also of great importance to the tourist's experience during the journey that the infrastructure should also offer reliable communications and that valuable environments along the journey should have been preserved.

The tourist industry must reach out with information in order to attract visitors. This involves signposting or signs as well as maps, brochures and digital information, to assist the customer in finding his destination.

Scope for communication and dialogue with regulatory bodies and authorities is of great importance to the tourist industry. Since the group consists of many different types of companies, it may be difficult for the customer group to convey its views and achieve consensus of views.

\section{Present situation analysis and cooperation with the tourist industry}

\subsection{Tourist Councils}

Four out of the six STA regions already have active cooperation with the tourist industry at strategic level, through bodies known as Tourist Councils. The purpose of the Tourist Councils is to improve the exchange of experience and to devote joint work to the development of the tourist industry in the region. The issues are based on the needs of the tourist industry and may cover all activities. The Tourist Councils are also an important forum for disseminating information from the STA concerning current activities that may affect the tourist industry in various ways.

An important point of departure for achieving success is that everyone participating in the Council has a sense of responsibility for developing the cooperation. The fact that the tourist industry appoints its own representatives to the Tourist Councils and that the Council initiates and runs joint development projects has contributed to increased involvement of all members of the Councils.

\subsection{Cooperation at county level}

The Swedish Road Administration, together with regional representatives of the tourist industry, has been working in county-specific preparation groups for tourist signposting. The objective of the preparation groups is to assess the destinations that are of high tourist value in each county, and then provide special tourist signposting to these destinations. The work of the preparation 
groups was initially extensive as regards preparing inventories and prioritizing destinations that are of interest to tourists. There are currently signposting plans for almost all counties, and only occasional new applications are received every year. The experience from most of the counties shows is that the responsibilities of the preparation groups ought to be expanded if cooperation is to be effective. In the counties in which cooperation has been expanded to also include quality follow-up of the decided signposting, the results have been very positive.

\subsection{Examples of joint projects}

Cooperation with the tourist industry has also contributed to the setting up of joint development projects. In many cases, it has been difficult for the STA to define the role that the authority should play in these projects. Although the initial intention was that the STA should play a supportive rather than a driving role, a balance may be difficult to achieve at times. A few examples of completed or ongoing cooperation projects are given below:

- Cycle routes that connect several regions of high tourist interest, such as the South-East Route along the east coast of southern Sweden and the Kattegat Route along the west coast. Funds are seldom allocated in the national plans for new cycle routes. The work presupposes close cooperation between different road authorities, so that state and private roads can be linked together into a cycle traffic network.

- Diversions along busy roads that enable the tourist to choose an alternative road that allows for a slower pace and offers greater scope for discovering places of interest along the road. The work on diversions is still at a pilot study stage. Discussions have so far been concerned with determining whether travellers require alternative roads for a slower pace of the journey, and with who is to be responsible for developing and maintaining the tourist destinations along these stretches of road.

- The regional office of the Swedish Road Administration in Central Sweden, together with the Idre mountain and ski resort in the County of Dalarna and the Regional association in Dalarna, have started cooperation aimed at giving examples of how a tourist facility that is almost entirely dependent on road transport can be sustainably adapted. During the course of the cooperation, consideration was give to everything from the journeys of the personnel within the region to how tourists can travel to Idre without a car and how they can move within the region between their accommodation and the ski slopes. The responsibility of the STA was to provide support, for instance, in the preparation of personnel training and sustainable adaptation of transport.

\subsection{Planning of infrastructure}

The STA, together with regional representatives of the tourist industry, has produced regional system analyses that describe the infrastructure needs of the tourist industry. This work serves as the basis for the national plan for Transport System 2010-2021 [1]. The work of producing joint system analyses has been 
coordinated within the framework of the activities of the tourist councils in the regions that have established councils. In other regions, temporary groups have been set up to produce the source information.

The work on regional system analyses has revealed that the STA calculation models and travelling habit investigations have been insufficient for describing the effects of the planned expansion of the tourist industry within a region or within a destination.

\section{Targets for the tourist industry}

In the work of producing a strategy for the tourist industry, the STA has drawn up targets for continued cooperation with the tourist industry, on the basis of the present situation analysis carried out. The targets are described in the form of general targets for the work on tourist matters and detailed targets for the cooperation.

General targets:

- The transport system shall support growth throughout the country

- The tourist industry shall recognize that the dialogue with the STA on infrastructure matters supports the development of the industry

- The transport system shall be developed so that it supports sustainable and safe journeys to and within destinations

- The information on the STA homepage shall be easily accessible to the tourist industry

Detailed targets for the cooperation:

- Tourist councils shall be available regionally to support the development of the industry

- Decisions on important changes in the transport system (that affect the tourist industry) shall be preceded by a dialogue with the industry

- Formalized cooperation shall be established at county level for developing and handling matters related to the signposting system.

It is important to describe together the activities and measures that shall be carried out in order to achieve the targets set up and to develop forms for continual follow up of the targets.

\section{Continued work and expected results}

In the continued work on the strategy for the tourist industry, it is important to focus on developing common ways of working for cooperation at regional and county levels. Common ways of working are an important prerequisite for achieving national impact in matters that are of major importance to the tourist industry. The need for developing tools for being better able to describe the effects that investments in new tourist destinations have on the infrastructure is an example of the issues that the various regional tourist councils need to pursue jointly. 
We have produced proposals for the ways of working, objectives and responsibilities for regional tourist councils and county-specific forums for tourist signposting and signs in cooperation with tourist industry. The proposals for joint ways of working will be used as a basis for the agreement of every council/forum on the ways of working, objectives and responsibilities.

A brief summary of the proposals for the ways of working of the various groups is given below.

The activities of the tourist councils are aimed at:

- Safeguarding established contact paths to the tourist industry in the region

- Mutual exchange of knowledge concerning the needs and planned changes that could affect the infrastructure or the development of the industry

- $\quad$ Ensuring that the views of the tourist industry are weighed in as a parameter in the planning of the infrastructure on the same terms as other customer groups

The work is led and coordinated by an appointed person from the STA. The agenda for the meeting is set on the basis of the tourist industry needs and the needs of the STA for communicating and discussing ongoing activities.

The county-specific forums for tourist signposting and signs are aimed at:

- Safeguarding established contact paths to the tourist industry in the county

- Developing the cooperation in tourist signposting and signs

- Contributing to decisions concerning tourist signposting and signs being taken on the basis of good source information

- Contributing to good knowledge of the quality shortcomings in tourist signposting and signs

- Contributing to a consensus of opinion concerning tourist signposting and signs across county boundaries

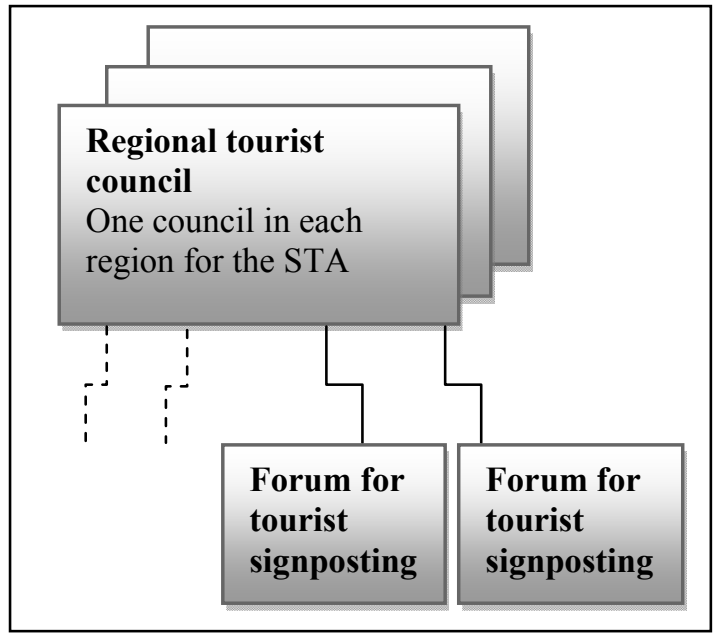

Figure 1: Schematic for the cooperation between the tourist industry and the STA in each region. 
The work is led and coordinated by the Tourism Manager in each county, who is also included in the regional tourist council. STA employees participate in the work of the forum and are responsible for taking away the recommendations drawn up by the forum in the work of dealing with signposting matters. If the forum considers that certain matters need to be transferred to the regional tourist council, this is done through the Tourism Manager of the county.

\section{Expected results}

Experience from regions that have had established cooperation for some years indicates that the work in the tourist councils and county-specific forums has contributed to drawing attention to common problems and development opportunities. The periodic meetings in councils or forums demand that the participants tackle the various issues between meetings. The demands made on the STA and the opportunities available for us to support the tourist industry in its efforts to develop the industry will gradually increase due to the improved collaboration.

A condition for continued collaboration is that all members consider that the joint work is effective and leads to some form of result. The interest in participating in tourist councils and county-specific forums will otherwise quickly diminish. The ability of the STA to meet the needs of the tourist industry by new infrastructure investments is not expected to increase to the same extent as the requirements from the industry. The STA and the tourist industry thus face the major challenge of finding traffic-type bridging solutions that do not rely solely on new investments.

\section{References}

[1] Swedish Rail Administration, Swedish Road Administration, Swedish Transport Administration and Swedish Maritime Administration. (2009). National plan for the transport system 2010-2021 - overall description of the effects of the national plan and county $\mathrm{pl}$. Stockholm.

[2] Swedish Road Administration. (2007). Customer group document for commerce and industry. Borlänge: Swedish Road Administration. 